\title{
Heterotopic pregnancy treated with methotrexate: case report
}

\begin{abstract}
Heterotopic pregnancy is defined by the simultaneous presence of an ectopic and intrauterine pregnancy. It is a relative common condition in women submitted to assisted reproduction techniques $(1: 100)$, but rare when the conception occurs in a spontaneous manner $(1: 30.000)$.

Its presence is connected to mechanical and/or functional factors that make the passage of the embryo to the uterus difficult. The early diagnosis is difficult due to the imprecise symptoms, but, when done late, may evolve with serious complications. This report deals with the treatment of a spontaneous heterotopic pregnancy done with methotrexate and with good evolution. The fetus was born at 34 weeks and had as a complication a hypospadias I.
\end{abstract}

Keywords: congenital abnormalities, heterotopic pregnancy, methotrexate
Volume 10 Issue 2 - 2019

\section{Adriane Castro,' Gustavo Keiti Susuki, ${ }^{2}$ Juliana de Luna Vasel, ${ }^{2}$ Leonardo Marcon Guedes $^{3}$}

'Department of Obstetrics and Gynecology, Hospital Santa Cruz, Curitiba, PR, Brazil

2 Medical student at Positivo University, Curitiba, PR, Brazil ${ }^{3}$ Academician of Medicine of Positivo University, Curitiba, PR, Brazil

Correspondence: Adriane Castro, Secretary, Department of Obstetrics and Gynecology, Hospital Santa Cruz, Curitiba, PR, Brazil,Email adrianecastro@live.com

Received: March 28, 2019 | Published: April 09, 2019

\section{Introduction}

Heterotopic pregnancy (HP) is defined as the presence of an intrauterine pregnancy concurrently with an ectopic pregnancy (EP). ${ }^{1}$ It is a rare condition that happens in about $0.6-2.5$ cases in each 10,000 pregnancies. ${ }^{2}$ When it happens, the most frequent site for the ectopic implantation is the fallopian tube. ${ }^{3}$ In this situation, the early diagnosis is very difficult, happening usually after the rupture of the EP.,

The incidence of this abnormality in increasing and is related to the popularization of the assisted reproduction techniques. ${ }^{2}$ Besides, this is also connected to mechanical and/or functional factors that make the passage of the embryo to the uterine cavity difficult, such as a pelvic inflammatory disease, tube adherences, and previous history of surgeries in the fallopian tubes or EP. ${ }^{6}$

\section{Case description}

P.L.S.M., female, 34 years old, Brazilian, chronological pregnancy 4 weeks and 5 days pregnant, looked for medical assistance for dysuria, bladder repletion, polaciuria, and pressure pain in the hypogastrium for more than 20 days, using nitrofurantoin. Beta-hCG performed 1 day before by an external service showed $6509.4 \mathrm{mUI} / \mathrm{mL}$. She had had a prior pregnancy with caesarian section delivery.

During the examination, the patient presented good general state, flat abdomen, flaccid, painful to touching on the hypogastrium, without resistance, bowel sounds present and fetal heartbeats (FHB) inaudible at fetal heart monitoring. During the gynecological examination, a lumpy whitish substance was found with mucosal hyperemia.

Transvaginal ultrasonography (TVUS) at admission detected "non observation of image compatible with gestational sac inside the uterine cavity. Image suspected of RP in the left annex measuring about $18 \times 18 \times 16 \mathrm{~mm}$ ". Renal and hepatic function without alterations. The patient was hospitalized and received 1 dosage of methotrexate (MTX) $50 \mathrm{mg} / \mathrm{m}^{2}$ for the treatment of the EP. Beta-hCG quantitative of $9669.23 \mathrm{mUI} / \mathrm{mL}$ after medication. The hospitalization continued with a good evolution and dismissal happened a day after the medication, with the request for return in 4 to 7 days for the control of beta-
hCG. A vaginal topic treatment was prescribed with association of metronidazole $750 \mathrm{mg}$ and miconazole $150 \mathrm{mg}$ for 7 days.

After 4 days, the patient returns with complaints of high intensity shooting pain in the lower abdomen, without vaginal bleeding. BetahCG showed $17,941 \mathrm{mUI} / \mathrm{mL}$. There was a suspicion of failure of the MTX treatment.

\section{During the examination}

Regular general state, good color, hydrated, afebrile, stable vital signs stable, flat abdomen, flaccid, painful to hypogastrium touching, and without signs of peritoneal irritation. Gynecological examination without alterations. Video laparoscopy to terminate the GP prescribed.

In the preoperative, a new TVUS showed "involution of image suggesting GP in the left annex; a small cystic image inside the uterine cavity, which could correspond to a second initial gestational sac". After this result associated to the ascending beta-hCG, the surgical plan was suspended for investigation of the GP and hospital release with outpatient follow-up.

Seven days after the suspension of the video laparoscopy, exams showed "topical gestational sac, embryo with FHB, absence of adnexal image" and beta-hCG $>15,000 \mathrm{mUI} / \mathrm{mL}$. Fifteen days later, a follow up TVUS, showed a "topical and single gestation, estimated in 7 weeks by the CCN measuring; embryo with FHB present".

The topical gestation evolved with a fetus showing a restriction of symmetric intrauterine growth since 16 weeks of gestation, normal Doppler. It was decided to terminate the gestation at 34 weeks, due to the absence of fetal weight gain in the last week. A caesarian section was performed without complications of a male fetus, APGAR 9/10, parkin 33 weeks; weight 1580 grams, presenting hypospadias.

The patient authorized the publication of this case.

\section{Discussion}

GP is a rare condition, which, when spontaneous, has an incidence estimated in 1:30.000. The utilization of assisted reproduction 
techniques increases this risk to values close to $1: 100 .{ }^{7}$ The most common places of extra uterine implantation are the ampoule $(70 \%)$, followed by the isthmus (12\%) and can also be corneal, cervical, ovarian, abdominal, or in a caesarean scar. ${ }^{8,9}$

The main risk factors identifiable for HP occurrence are similar to the ones for an EP, that is, the ones that may make the passage of the embryo to the uterine cavity difficult. They are: pelvic inflammatory disease, advanced age, previous history of surgery in the fallopian tubes, tube adherences, uterine malformations, and the use of assisted reproduction techniques. ${ }^{2,6,10}$

The symptoms are varied, non-specific, and dependent on the embryo's stage of development. The most common are abdominal pain, adnexal mass, and hypovolemic shock. According to Segundo Reece et al., four symptoms are useful for the diagnosis of tubal GP: adnexal mass, abdominal pain, enlarged uterus, and peritoneal irritation. Because the endometrium is intact, vaginal bleeding is uncommon, different from what is seen in EP.,11 Besides, biochemical markers, beta-hCG and progesterone, which are useful for the EP diagnosis, do not work for the HP diagnosis, as the intrauterine trophoblastic tissue is producing normal quantities of those hormones. ${ }^{12}$

TVUS is the golden standard for the diagnosis, but, when done in precocious gestational ages, the presence of an intrauterine pregnancy may mask and deviate the attention to the occurrence of HP. ${ }^{13}$ Even so, only $26 \%$ of those pregnancies are diagnosed by ultrasound. ${ }^{14}$

The diagnosis, in $70 \%$ of the cases, is done between the $5^{\text {th }}$ and the $8^{\text {th }}$ weeks, while in the others, between the $11^{\text {th }}$ and $12^{\text {th }}$ weeks. ${ }^{12}$ When the diagnosis is late, there is a risk of it becoming a serious life threatening emergency. ${ }^{7}$ Different diagnosis include appendicitis, rupture of luteinic cyst, ectopic pregnancy, and nephrolithiasis. ${ }^{15}$

Because it is a rare condition, there are no standard recommendations for the hP treatment. The available options include laparotomy when the patient is hemodynamically unstable, or there is a suspicion of hemoperitonium. The use of potassium chlorate is a local therapy to be considered. The surgical option is the most common approach. ${ }^{16}$

The treatment of the ectopic pregnancy must be adequate to the place of implantation, be the least invasive possible, with minimum uterine manipulation, to preserve the concomitant topic pregnancy. In women where there is contralateral tube integrity, the salpingectomy by laparoscopy is described as the preferred treatment. In the presence of hemodynamic instability, hemoperitoneum or intense pain, the first option becomes laparotomy. ${ }^{15}$ The use of methotrexate is a topic pregnancy is known, is contrarindicated. ${ }^{17}$

In the reported case, the first therapeutic approach was made to terminate the EP. The main criteria for the indication of MTX are: adnexal mass diameter smaller or equal to $3.5 \mathrm{~cm}$, absence of fetal cardiac activity, beta-hCG $<5000 \mathrm{mUI} / \mathrm{MI}$, hemodynamic stability, absence of intense or persistent abdominal pain, normal hepatic and renal functions, project for future pregnancy, and consent term signed. ${ }^{14,18}$ If all these criteria are met, MTX can be administered in a single $50 \mathrm{mg} / \mathrm{m}^{2}$ intramuscular dosage. The follow up continues with serial dosage of beta-hCG in the day of its administration, $4^{\text {th }}$ and $7^{\text {th }}$ days after the use of the drug. When the titles remain the same or increase, there is a diagnosis of persistence of the trophoblastic tissue. Signs that indicate failure of the treatment or suspicion of tubal rupture, such as hemodynamic instability, increasing of abdominal pain, or elevation of beta-hCG after MTX, advocate the abandonment of the clinical treatment. ${ }^{14}$

The elevation of beta-hCG $(17.941 \mathrm{mUI} / \mathrm{mL})$ in the $4^{\text {th }}$ day after the administration of MTX together with the compatible image of an intrauterine gestational sac and the involution of the EP in the left annex raised the hypothesis of an HP, with a new dosage of MTX contraindicated.

MTX is an antagonist of the folic acid, causing the decreasing of the necessary elements for the synthesis of deoxyribonucleic acid (DNA) and ribonucleic acid (RNA). ${ }^{19,20}$ Its action mechanism makes it effective against the development of the trophoblast. In animals, studies showed its use as an inductor of congenital defects. It should, therefore, be avoided in human pregnancies (category X). ${ }^{21}$ The anomalies associated to its use involve the central nervous system (spina bifid, hydrocephaly, anencephaly, and mental retardation); skeletal abnormalities (partial or absent ossification of bones, micrognathia, cleft lip or palate, depression of nasal bone, hypertelorism, short limbs, sindactilia, congenital club foot), dextrocardia, and delay of intrauterine growth. ${ }^{22}$ Cases of hypospadias, congenital diaphragmatic hernia, or craniossinostosis were also reported. ${ }^{23}$ In the long run, according to a study by Aviles et al.-where children exposed to MTX in the prenatal period, the neurological, psychological, hematological, physical, and immunological functions were normal between 3 and 19 years of age. ${ }^{24}$

After the use of MTX for the treatment of EP, even if there is no consensus in the literature, a new pregnancy is not recommended during a period of three to six months, for its presence in the liver may last up to 116 days after the exposition. ${ }^{23}$

The presence of an EP associated to an intrauterine one brings a series of risks to the pregnant woman and the vitality of the embryo. The delay in the diagnosis may bring serious complications due to the bigger risk of tubal rupture with evolution to hypovolemic shock. ${ }^{25}$ The lack of knowledge of a topic pregnancy concomitant to an ectopic one may culminate with the end of the intrauterine pregnancy in evolution, if a curettage is performed in an inadvertent manner. According to Dor et al., when compared to normal pregnancies, the heterotopic one result in a reduction of $30 \%$ of the live births. ${ }^{12}$

In the presence of abdominal pain in the first trimester of a pregnancy, it is fundamental that the professional think of a heterotopic pregnancy as a differential diagnosis. This case report contributes to the medical practice, since it alerts the professionals to the clinical suspicion and revises fundamental aspects for the correct treatment. Inadequate therapies increase the risk of malformations and even the failure of the topic pregnancy.

\section{Conclusion}

In this case report, the importance of the diagnosis of the heterotopic pregnancy was demonstrated. Even though it is rare, such hypothesis must be investigated, mainly in the cases of abdominal pain during the first trimester and in cases of assisted reproduction. This way, complications caused by the late diagnosis and instituted treatments will be avoided.

\section{Acknowledgments}

None. 


\section{Conflicts of interest}

Author has no any conflict of interest to declare.

\section{References}

1. DeVoe RW, Pratt JH. Simultaneous intrauterine and extrauterine pregnancy. Am J Obstet Gynecol. 1948;56(6):1119-1126.

2. Noor N, Bano I, Parveen S. Heterotopic pregnancy with successful pregnancy outcome. J Hum Reprod Sci. 2012;5(2):213-214.

3. Tal J, Haddad S, Gordon N, et al. Heterotopic pregnancy after ovulation induction and assisted reproductive technologies: a literature review from 1971 to 1993. Fertil Steril. 1996;66(1):1-12.

4. Umranikar S, Umranikar A, Rafi J, et al. Acute presentation of a heterotopic pregnancy following spontaneous conception: a case report. Cases J. 2009;2:9369.

5. Korkontzelos I, Antoniou N, Stefos T, et al. Rupture heterotopic pregnancy with successful obstetrical outcome: a case report ande review of the literature. Clin Exp Obstet Gynecol. 2005;32(3):203-206.

6. Govindarajan MJ, Rajan R. Heterotopic pregnancy in natural conception. J Hum Reprod Sci. 2008;1(1):37-38.

7. Eom JM, Choi JS, Ko JH, et al. Surgical and obstetric outcomes of laparoscopic management for women with heterotopic pregnancy. $J$ Obstet Gynaecol Res. 2013;39(12):1580-1586.

8. Brown J, Wittich A. Spontaneous heterotopic pregnancy successfully treated via laproscopic surgery with subsequent viable intrauterine pregnancy: a case report. Military medicine. 2012;177(10):1227-1230.

9. Reece EA, Petrie RH, Sirmans MF, et al. Combined intrauterine and extrauterine gestations: a review. Am J Obstet Gyencol. 1983;146(3):323330.

10. Clayton HB, Schieve LA, Peterson HB, et al. A comparison of heterotopic and intrauterine-only pregnancy outcomes after assisted reproductive technologies in the United States from 1999 to 2002. Fertil Steril. 2007;87(2):303-309.

11. Alptekin H, Dal Y. Heterotopic pregnancy following IVF- -ET: successful treatment with salpingostomy under spinal anesthesia and continuation of intrauterine twin pregnancy. Arch Gynecol Obstet. 2014;289(4):911-914.

12. Dor J, Seidman DS, Levran D, et al. The incidence of combined intrauterine and extrauterine pregnancy after in vitro fertilization and embryo transfer. Fertil Steril. 1991;55(4):833-834.
13. Lima T, Dias C, Oliveira T. Heterotopic Pregnancy: urgent ultrasonographic diagnosis. Acta Obstet Ginecol Port. 2016;10(2):160-161.

14. Elito JJ, Montenegro NAMM, Soares RDC, et al. Ectopic pregnancy not routed: diagnosis and treatment. Current situation. Revista Brasileira de Ginecologia e Obstetrícia. 2008;30(3):149-159.

15. Magalhães M, Areia A, Franco S, et al. Late diagnosis of heterotopic pregnancy after spontaneous conception: about a clinical case. Acta Obstet Ginecol Port. 2015;9(4):293-296.

16. Wright A, Kowalkzyc CL, Quintero R, et al. Selective embryo reduction in a heterotopic pregnancy using potassium chloride injection resulting in a hematosalpinx. Fertil Steril. 1996;66(6):1028-1030.

17. Louis-Sylvestre C, Morice P, Chapron C, et al. The role of laparoscopy in the diagnosis and management of heterotopic pregnancies. Hum Reprod. 1997;12(5):1100-1102.

18. Silva-Filho AL, Rodrigues PP, Rezende CP. What are the criteria for drug treatment in ectopic pregnancy? Revista da Associação Médica Brasileira. 2006;52(6):383.

19. Calabresi P, Chabner BA. Antineoplastic agents. In: Gilman A, Goodman LS, Goodman A, editors. The pharmacologic basis of therapeutics. 8th ed. New York: MacMillan; 1990:1275-1276.

20. Barnhart K, Coutifaris C, Esposito M. The pharmacology of methotrexate. Expert Opin Pharmacother. 2001;2(3):409-417.

21. Loyd ME, Carr M, Mcelhatton P, et al. The effect of methotrexate on pregnancy, fertility and lactation. Q J Med. 1999;92(10):551-563.

22. Ostensen M, Khamashta M, Lockshin M, et al. Anti-inflammatory and immunosuppressive drugs and reproduction. Arthritis Res Ther. 2006;8(3):209.

23. Hackmon R, Sakaguchi S, Koren G. Effect of methotrexate treatment of ectopic pregnancy on subsequent pregnancy. Can Fam Physician. 2011;57(1):37-39.

24. Aviles A, Diaz-Maqueo JC, Talavera A, et al. Growth and development of children of mothers treated with chemotherapy during pregnancy: current status of 43 children. Am J Hematol. 1991;36(4):243-248.

25. Barrenetxea G, Barinaga-Rementeria L, Lopez de Larruzea A, et al. Heterotopic pregnancy: two cases and a comparative review. Fertil Steril. 2007;87(2):417. 